\title{
43. Phytoalexin Production in Barley Powdery Mildew as Affected by Thermal and Biological Predispositions
}

\author{
By Hachiro OKu, Seiji Ouchi, Tomonori ShIRAISHI, \\ Toshikazu BABA, and Hiroshi MiYagawA \\ Laboratory of Plant Pathology, Faculty of Agriculture, Okayama University
}

(Comm. by Naohide Hiratsuka, M. J. A., March 12, 1975)

Phytoalexins, antifungal substances produced in higher plants as a result of fungal infection, have been the subject of discussion for a long time from the viewpoint of the defence mechanism of host against parasite, but nothing is known about their roles in obligate parasitic diseases.

In the series of studies on the mechanism of host specificity of plant pathogenic fungi, we recently demonstrated two phases of phytoalexin accumulation during the pathogenesis of barley powdery mildew, a typical obligate parasitic disease. ${ }^{4)}$ The first phase phytoalexin which is induced at very early stage of infection in incompatible cultivar-race combination may probably concern with the resistant mechanism of host against infection establishment. The second phase phytoalexin produced at the later stage in the host tissues surrounding the compatible fungal colony obviously concerns with the resistance against colony development. In the other papers, we reported that heat treatment of barley leaves at $45 \mathrm{C}$ for $20 \mathrm{~min}$ before inoculation $^{7)}$ or preliminary inoculation with compatible races ${ }^{5}$ ) rendered primarily resistant barley leaves susceptible.

This communication aimes at elucidating the role of first phase phytoalexin in the infection establishment of powdery mildew fungus by estimating the phytoalexin producing ability of primarily incompatible hosts under the conditions that induce susceptibility.

Effect of heat treatment on phytoalexin accumulation in incompatible barley-powdery mildew combinations. Eight days-old seedlings of Hordeum vulgare L. cv. H.E.S.4, Russian 74, and an isogenic line derived from crossing Kobinkatagi (compatible with race 1) with Hordeum spontaneum nigrum (immune to race 1) (Isonig.) were heat-treated and inoculated with the conidia of Erysiphe graminis DC. f. sp. hordei Marchal, race 1, and subjected to the determination of compatibility and phytoalexin activity. The frequency of spores elongating secondary hyphae (ESH frequency, \%) and the growth rate of secondary hyphae ( $\mathrm{SH}$ length, $\mu \mathrm{m}$ ) were calculated 
Table I. Effect of heat treatment on the infection establishment of barley powdery mildew fungus, race 1

\begin{tabular}{clcc}
\hline Heat Dosage & Cultivar & $\begin{array}{c}\text { ESH frequency } \\
(\%)\end{array}$ & $\begin{array}{c}\text { SH length } \\
(\mu \mathrm{m})\end{array}$ \\
\hline \multirow{3}{*}{ None (Control) } & Isonig. & 0.2 & 111.5 \\
& Russian 74 & 4.0 & 152.8 \\
& H. E. S. 4 & 1.4 & 102.4 \\
45 C-30 min & Isonig. & 10.5 & 100.0 \\
& Russian 74 & 25.4 & 110.7 \\
& H. E. S. 4 & 12.5 & 132.9 \\
\hline
\end{tabular}

Hosts were heated $1 \mathrm{hr}$ before inoculation.

ESH frequency and SH length were measured $48 \mathrm{hr}$ after inoculation.

Table II. Effect of heat treatment* on phytoalexin production of incompatible barley-powdery mildew combinations

\begin{tabular}{|c|c|c|c|}
\hline \multirow{2}{*}{\multicolumn{2}{|c|}{ Host-parasite combination }} & \multicolumn{2}{|c|}{$\begin{array}{l}\text { Inactivation indices** by heat treatment } \\
\text { at each time after inoculation }\end{array}$} \\
\hline & & $8 \mathrm{hr}$ & $12 \mathrm{hr}$ \\
\hline & Isonig.-race 1 & $13.0-\infty$ & $3.1-3.7$ \\
\hline & Russian 74 -race 1 & $1.9-2.2$ & $3.4-\infty$ \\
\hline & H. E.S. 4 -race 1 & $4.4-8.0$ & $10.6-\infty$ \\
\hline & \multicolumn{3}{|c|}{$\begin{aligned} \text { Hosts were treated } 1 \mathrm{hr} \text { before inoculation at } 45^{\circ} \mathrm{C} \text { for } 30 \mathrm{~min} . \\
\text { Inactivation index }=\frac{\% \text { of nongermination in diffusate from leaves of }}{\% \text { of nongermination in diffusate from leaves of }} \\
\\
\text { (nontreated, inoculated-nontreatd, noninoculated) } \\
\text { (treated, inoculated-treated, noninoculated) }\end{aligned}$} \\
\hline
\end{tabular}

by the method reported previously.5)

As shown in Table I, all cultivars, especially Isonig. were incompatible with race 1 showing ESH frequency less than 4.0, but the ESH frequency increased to more than 10.5 by heat treatment, signifying partial breakdown of resistance to infection. The SH length, however, was not affected.

The phytoalexin activity was estimated on the basis of conidial germination of race 1 on the phytoalexin-impregnated agarose block as reported previously.4) The result is shown in Table II. The inactivation index was calculated by the method shown in the Table.

The simultaneous breakdown of resistance and phytoalexin producing ability of incompatible barley leaves by heat treatment suggests a possible participation of phytoalexin in the rejection reaction in the powdery mildew infection. The fact that SH length is not affected by scalding does not necessarily mean the unimportance of phytoalexin in the resistance against hyphal elongation because spores 
once established infection could ordinarily elongate secondary hyphae, at least in the early phase, as if they are compatible. ${ }^{5)}$

Effect of accessibility and resistance induction on phytoalexin production. Induction of resistance in primarily compatible host by preliminary inoculation with an incompatible fangal race has been well known phenomenon and often referred to as cross-protection, and this was also applicable to powdery mildew of barley. On the contrary, preliminary inoculation with a compatible race rendered barley leaves susceptible to a primarily incompatible race, and we termed this phenomenon as accessibility induction. ${ }^{5)}$

To elucidate the effect of accessibility or resistance induction on phytoalexin production, a barley cultivar, Kobinkatagi, was first inoculated with compatible (race 1 ) or incompatible race (E. graminis f. sp. tritici, race t2) for $48 \mathrm{hr}$, the inoculum was removed and then inoculated with a second race. The effect of the first inoculation on the phytoalexin induction in response to the second fungus was compared (Fig. 1).

The production of the first phase phytoalexin in incompatible interaction was suppressed when the barley leaves was primarily inoculated with a compatible race. In other words, a suppression of phytoalexin production occured by accessibility induction. Conversely, the preliminary inoculation with an incompatible race destined

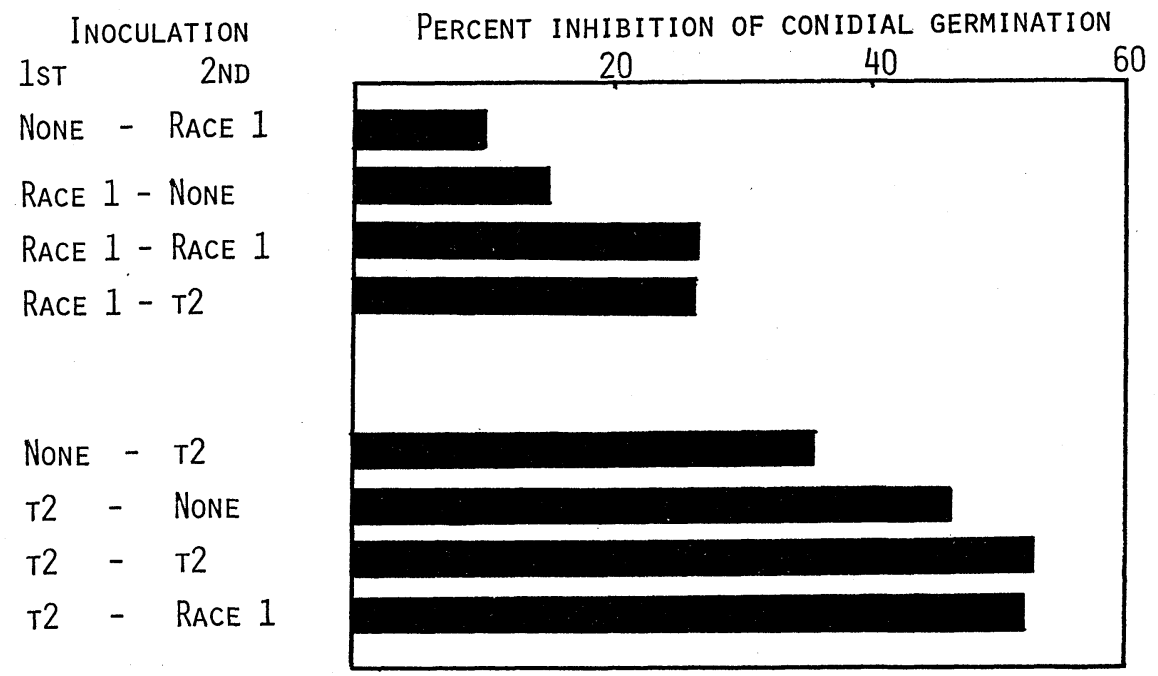

Fig. 1. Effect of accessibility and resistance induction on phytoalexin production in barley leaves

Accessibility (or resistance) was induced in barley leaves (cv. Kobinkatagi) by inoculation with race 1 (or t2) and phytoalexin production was estimated $12 \mathrm{hr}$ after second inoculation. 
the leaves to produce the same level of phytoalexin on subsequent inoculation with a compatible race as those challenged by an incompatible race. The same type of observation was made by Varns and Kuc in late blight disease of potato, a facultative parasitic disease, and they concluded that susceptibility is an active process that suppress the resistance response. ${ }^{9)}$ Thus the present result also incidates that phytoalexin would possibly be involved in the mechanism of rejection reaction in the barley powdery mildew.

We proposed the hypothesis that the primary recognition of host cells of invading microbes as compatible or incompatible is the most important event in the establishment of infection and the recognition might be controlled by some all-or-none type gene systems. ${ }^{5), 6)}$ Data presented in this communication is consistent with the above hypothesis, i.e., once host cells recognized a microbe as compatible phytoalexin production could not any more be ignited by the subsequent infection with an incompatible race. Conversely, once host cells were conditioned toward rejection phytoalexin was induced even if a compatible race came later. This fact also indicates that, unlike other diseases, ${ }^{1)-3), 9)}$ the decomposition of phytoalexin by compatible race could hardly account for the host specificity in barley powdery mildew.

This work is partially supported by a grant from the Ministry of Education of Japan (No. 936004). Financial support from Sankyo Co., Ltd. is also acknowledged.

\section{References}

1) Higgins, V. J., and R. L. Millar (1969): Phytopathology, 59, 1493-1499.

2) Higgins, V. J., S. Stoessl, and M. C. Heath (1974) : Phytopathology, 64, 105-107.

3) Nonaka, F. (1967) : Agr. Bull. Saga Univ., 24, 109-121.

4) Oku, H., S. Ouchi, T. Shiraishi, Y. Komoto, and K. Oki: Ann. Phytopath. Soc. Japan, 41 (in press).

5) Ouchi, S., H. Oku, C. Hibino, and I. Akiyama (1974): Phytopath. Z., 79, 24-34.

6) (1974): Phytopath. Z., 79, 142-151.

7) Ouchi, S., H. Oku, H. Nakabayashi, and K. Oka: Ann. Phytopath. Soc. Japan (in submission).

8) Van den Heuvel, J., and H. D. Van Etten (1973) : Physiol. Plant Path., 3, 327-339.

9) Varns, J. L., and J. Kuć (1971) : Phytopathology, 61, 178-181. 